\title{
Neutrophil to lymphocyte ratio in predicting short-term mortality in hemodialysis patients
}

\author{
Emre Erdem $^{\text {b* }}$, Coskun Kayaa, Ahmet Karatasa, Melda Dilek ${ }^{\mathrm{a}}$, Tekin Akpolat ${ }^{\mathrm{a}}$ \\ a Department of Nephrology, Faculty of Medicine, Ondokuz Mayls University, Samsun, Turkey \\ ${ }^{b}$ Department of Nephrology, Trabzon Kanuni Education and Research Hospital, Trabzon, Turkey
}

ARTICLE INFO ABSTRACT

\section{Article History \\ Received $\quad 27 / 03 / 2013$ \\ Accepted $\quad 12 / 05 / 2013$}

\section{* Correspondence to: \\ Emre Erdem \\ Department of Nephrology, \\ Trabzon Kanuni Education and Research \\ Hospital, Trabzon, Turkey \\ e-mail: emredlk@yahoo.com}

\begin{abstract}
Patients with end stage renal disease have a higher risk of mortality compared with the general population. The aim of the present study was to determine the value of neutrophil to lymphocyte ratio (NLR) in predicting mortality in hemodialysis patients. Fifty nine patients undergoing hemodialysis in our institution between January 2011 to June 2012 were analyzed. Baseline NLR, patient demographic, clinical, and biochemical parameters were obtained. The baseline median NLR value was 3.48. Patients were divided into two groups: Those with a NLR less than 3.48, and those greater than 3.48. The high NLR group had overall lower serum albumin levels $(\mathrm{p}=0.009)$ and higher $\mathrm{C}$ reactive protein levels $(\mathrm{p}=0.03)$. Seven $(11.9 \%)$ patients died, and all were in the high NLR group $(\mathrm{p}=0.01)$. Hemodialysis patients with high NLR levels have increased risk of short term mortality.
\end{abstract}

J. Exp. Clin. Med., 2013; 30:129-132

Keywords:

$\mathrm{C}$ reactive protein

Hemodialysis

Mortality

Neutrophil to lymphocyte ratio

Serum albumin

\section{Introduction}

Patients with end stage renal disease (ESRD) have a higher risk of mortality compared with the general population (Villar et al., 2007). Cardiovascular disease (CVD) is the major cause of mortality in ESRD, and carries a higher risk than the general population (Foley et al., 1998). The development of a risk profile for CVD in ESRD patients has been attempted. Risk factors used as such include: $\mathrm{C}$ reactive protein (CRP) (Owen and Lowrie, 1998), serum myeloperoxidase (KalantarZadeh et al., 2006), and white cell count and lymphocyte count (Reddan et al., 2003; Johnson et al, 2005). Neutrophil to lymphocyte ratio (NLR) has been used to predict mortality and prognosis in certain diseases (Zahorec, 2001; Bhutta et al., 2011; Kamisli et al., 2012).

NLR can be an indicator of systemic inflammation (Zahorec, 2001) and has been found to be a useful marker in mortality prediction in both cardiac (Núñez et al., 2008; Muhmmed Suliman et al., 2010; Uthamalingam et al., 2011) and noncardiac disease (Aliustaoglu et al., 2010; Azab et al., 2012). Also, NLR may be useful to predict adverse outcomes in several medical (Azab et al., 2011; Azab et al., 2012; Koçyigit et al., 2012) and surgical conditions (Bhutta et al., 2011). Our aim was to determine the value of NLR in predicting all-cause mortality in hemodialysis patients.

\section{Materials and methods}

Our study was performed in January 2011 with patients undergoing hemodialysis in our institution. Patients with active infection and hematologic disorders at the beginning of the study were not enrolled. Also, patients undergoing kidney transplantation, transferred to peritoneal dialysis and leaving the institution for another hemodialysis center during the follow-up were excluded. We included fifty nine patients into the study. All patients were followed until June 2012. During this follow-up period; a total of seven patients died.

All blood samples were taken in January 2011. Single 
pool Kt/V (spKt/V) values were recorded. NLR was calculated from the differential count, dividing the absolute neutrophil count by the absolute lymphocyte count. Complete blood count analysis was performed in the same analyzer (Advia 2120i, Siemens, Germany). All biochemical analyses were performed by a single clinical laboratory.

All patients were followed until June 2012, to evaluate mortality rates. All deaths were accurately recorded, with the exact cause of death documented. For out of hospital deaths, family members were interviewed to determine the cause of death. "All-cause" mortality included death associated with a myocardial ischemic event, heart failure, cerebrovascular accident, arrhythmia, cancer, or infection.

All patients had undergone hemodialysis three times a week with bicarbonate-based dialysate, single-use, high flux membranes, with a mean duration of $3.8 \pm 0.2$ hours. spKt/V was calculated according to the Daugirdas method (Daugirdas,1993). Serum calcium levels were corrected for serum albumin as follows: Corrected total calcium $(\mathrm{mg} / \mathrm{dL})$ $=$ total calcium $(\mathrm{mg} / \mathrm{dL})+0.8 \times[4-$ Serum albumin $(\mathrm{g} / \mathrm{dL})]$ (National Kidney Foundation, 2003; K/DOQI clinical practice guidelines for bone metabolism and disease in chronic kidney disease).

Descriptive analyses were presented using the mean and standard deviation. The student's t-test was used to compare groups, with the Chi-square test used for categorical variables. Survival curves were estimated according to the Kaplan-Meier Method, and the log-rank test for univariate analysis of survival. A p-value of less than 0.05 was considered to be statistically significant.

\section{Results}

The mean age of 59 patients ( 35 male, 24 female) on hemodialysis was $55.6 \pm 16.1$ years. The mean duration of hemodialysis was $63.4 \pm 40$ months. ESRD etiology included: diabetes mellitus $(n=17)$, hypertension $(n=12)$ vesicoureteral reflux $(n=4)$, glomerulonephritis $(n=3)$, pyelonephritis $(n=2)$, polycystic kidney disease $(n=1)$, amyloidosis $(n=1)$, and unknown etiology $(\mathrm{n}=18)$.

The median NLR at the beginning of the study was 3.48. Patients were divided in two groups (above or below 3.48). In the group of patients with a higher NLR, serum albumin was lower (p:0.009) and CRP was higher $(\mathrm{p}=0.03)$ (Table 1). The mean follow up period was $15.5 \pm 4.0$ months. During this period, a total of seven $(11.9 \%)$ patients died. Five patients died because of CVD, one patient died because of sepsis and one patient died because of cancer complication. All seven patients died were in the higher NLR group $(p=0.01)$ (Table 1). According to the Kaplan Meier curve, patients with high NLR levels had a higher mortality rate (1 year overall survival $76 \%$ ), compared with patients with low NLR $(\mathrm{p}=0.006)$.

\section{Discussion}

Mortality from all causes and cardiovascular death in hemodialysis patients has been increasing (Foley et al., 1998; Villar et al., 2007). Dyslipidemia, left ventricular hypertrophy, diabetes mellitus, hypertension, and tobacco smoking contribute to atherosclerosis in the general population, are highly prevalent in patients with chronic kidney disease (CKD) (PecoitsFilho et al., 2002). However, traditional coronary risk factors
Table 1. Baseline demographic and laboratory parameters by NLR. F: female; M: male; BMI: body mass index; WBC: white cell count; CRP: C reactive protein; cCa: calcium corrected for serum albumin; NLR:neutrophil to lymphocyte ratio

\begin{tabular}{lccc} 
Characteristic & NLR $<$ median & NLR $\geq$ median & p-value \\
\hline & $(\mathrm{n}=29)$ & $(\mathrm{n}=30)$ & \\
Age (year) & $52 \pm 18$ & $59.1 \pm 13$ & 0.09 \\
Gender (F/M) & $13 / 16$ & $11 / 19$ & 0.52 \\
Duration on dialysis (months) & $73.2 \pm 76.3$ & $54.0 \pm 46.1$ & 0.25 \\
BMI $\left(\mathrm{kg} / \mathrm{m}^{2}\right)$ & $26.0 \pm 6.9$ & $27.8 \pm 5.1$ & 0.24 \\
Hemoglobin $(\mathrm{g} / \mathrm{dL})$ & $11.2 \pm 0.9$ & $11.1 \pm 0.9$ & 0.75 \\
WBC $\left(\mathrm{mm}^{3}\right)$ & $5380 \pm 1159$ & $7275 \pm 1903$ & 0.0001 \\
Neutrophil $\left(\mathrm{mm}^{3}\right)$ & $3285 \pm 817$ & $5282 \pm 1563$ & 0.0001 \\
Lymphocyte $\left.(\mathrm{mm})^{3}\right)$ & $1379 \pm 369$ & $1166 \pm 314$ & 0.02 \\
Platelets $\left(10^{3} / \mathrm{mm}^{3}\right)$ & $208 \pm 53$ & $237 \pm 73$ & 0.08 \\
Creatinine (mg/dL) & $9.8 \pm 2.3$ & $9.7 \pm 2.6$ & 0.83 \\
Phosphorus (mg/dL) & $6.1 \pm 1.4$ & $5.9 \pm 2.2$ & 0.73 \\
cCa (mg/dL) & $8.6 \pm 1.0$ & $8.7 \pm 0.7$ & 0.51 \\
cCa X Phosphorus (mg $\left./ \mathrm{dL}{ }^{2}\right)$ & $52.6 \pm 14$ & $52.0 \pm 19$ & 0.9 \\
Albumin (g/dL) & $4.0 \pm 0.2$ & $3.7 \pm 0.5$ & 0.009 \\
Triglycerides (mg/dL) & $197 \pm 108$ & $255 \pm 226$ & 0.21 \\
Total cholesterol (mg/dL) & $183 \pm 54$ & $176 \pm 53$ & 0.63 \\
CRP (mg/L) & $15.2 \pm 18.6$ & $7.0 \pm 6.6$ & 0.03 \\
Parathyroid hormone (pg/mL) & $409 \pm 377$ & $441 \pm 376$ & 0.74 \\
spKt/V & $1.2 \pm 0.2$ & $1.2 \pm 0.2$ & 1.0 \\
All cause death (n) & 0 & 7 & 0.01 \\
NLR & $2.4 \pm 0.6$ & $4.6 \pm 1.2$ & 0.0001 \\
\hline
\end{tabular}

in the general population do not correlate with atherosclerotic cardiovascular disease in hemodialysis patients (Cheung et al., 2000).

Additional parameters for risk stratification in hemodialysis patients can define the profile to determine cardiovascular events or overall mortality.

Inflammation may have a greater effect on CVD mortality than other factors (Pecoits-Filho et al., 2002). Recently, inflammation has been identified as a key player in atherosclerotic CVD, in populations with CKD (Pecoits-Filho et al., 2002). Inflammatory markers such as CRP (Noh et al., 1998; Owen and Lowrie, 1998) and interleukin-6 (Honda et al., 2012), were used to predict all-cause mortality in dialysis patients. NLR has been used as an another marker of systemic inflammation (Zahorec, 2001). NLR was used as an indicator to predict cardiovascular outcomes in patients with coronary artery disease (Núñez et al., 2008; Muhmmed Suliman et al., 2010; Uthamalingam et al., 2011), and showed increased mortality in breast, stomach, and pancreatic cancer patients (Aliustaoglu et al., 2010; Jung et al., 2011; Azab et al., 2012). NLR has also been used to predict adverse outcomes in acute pancreatitis and major vascular surgery (Azab et al., 2011; Bhutta et al., 2011). Increased neutrophil and reduced lymphocyte count has been associated with increased mortality in dialysis patients (Reddan et al., 2003; Johnson et al., 2005). Reddan and co- workers found an increased neutrophil number and reduced lymphocyte count to be independent predictors of mortality in hemodialysis patients (Reddan et al., 2003). The Dialysis Outcomes and Practice Pattern Study (DOPPS), an observational study of chronic hemodi- 
alysis patients showed lower baseline lymphocyte count and higher baseline and six-month increases in neutrophil count to be significantly associated with higher mortality (Pifer et al., 2002). Elevated white cell or neutrophil number was also found to be a significant predictor of all-cause and cardiac mortality in peritoneal dialysis (PD) patients, independent of clinical, biochemical, and inflammatory parameters (Johnson et al., 2005). Subsequently, the prognostic value of NLR in chronic PD patients has been examined, demonstrating NLR to be an independent predictor of all-cause and cardiovascular mortality in PD patients. Patients with higher NLR showed significantly increased overall and cardiovascular mortality rates compared with patients with lower NLR (An et al., 2012). We confirmed this observation in our study of mortality and NLR in hemodialysis patients.

The prognostic value of NLR in chronic dialysis patients is due to its being an inflammatory marker. It has been suggested that chronic inflammation is highly prevalent in ESRD (Zimmermann et al., 1999). Chronic inflammation may contribute to accelerated atherosclerosis. Acute-phase reactants and cytokines may promote atherogenesis directly, in conjunction with the inflammation associated with cardiovascular disease (Pecoits-Filho et al., 2002). Neutrophilia and lymphocytopenia appear after severe trauma, major surgery, severe sepsis, and systemic inflammation. NLR can be used as a simple laboratory hematological parameter for the evaluation of clinical status following sepsis, systemic inflammation, and critical illness (Zahorec, 2001).

In this study, we found a significantly higher CRP and lower serum albumin in the high NLR versus low NLR group, suggesting the potential effect of inflammation. A low serum albumin and a high CRP can also be seen in the "malnutritioninflammation-atherosclerosis" (MIA) syndrome. MIA is strongly associated with atherosclerotic cardiovascular disease and carries high morbidity and mortality in chronic kidney disease (Stenvinkel et al., 2000; Pecoits-Filho et al., 2002).

In conclusion, hemodialysis patients with a high NLR (greater than 3.5) have an increased short term overall mortality risk. NLR may be used as a predictor of all cause mortality in patients with ESRD.

\section{REFERENCES}

Aliustaoglu, M., Bilici, A., Seker, M., Dane, F., Gocun, M., Konya, V., Ustaalioglu, B.B., Gumus, M., 2010. The association of pre-treatment peripheral blood markers with survival in patients with pancreatic cancer. Hepatogastroenterology. 57, 640-645.

An., X., Mao, H.P., Wei, X, Chen, J.H., Yang, X., Li, Z.B., Yu, X.Q., Li, Z.J., 2012. Elevated neutrophil to lymphocyte ratio predicts overall and cardiovascular mortality in maintenance peritoneal dialysis patients. Int. Urol. Nephrol. 44, 1521-1528.

Azab, B., Bhatt, V.R., Phookan, J., Murukutla, S., Kohn, N., Terjanian, T., Widmann, W.D., 2012. Usefulness of the neutrophil-to-lymphocyte ratio in predicting short- and long-term mortality in breast cancer patients. Ann. Surg. Oncol. 19, 217-224.

Azab, B., Jaglall, N., Atallah, J.P., Lamet, A., Raja-Surya, V., Farah, B., Lesser, M., Widmann, W.D., 2011. Neutrophil-lymphocyte ratio as a predictor of adverse outcomes of acute pancreatitis. Pancreatology. 11, 445-452.

Azab, B., Daoud, J., Naeem, F.B., Nasr, R., Ross, J., Ghimire, P., Siddiqui, A., Azzi, N., Rihana, N., Abdallah, M., Azzi, N., Patel, P., Kleiner, M., El-Sayegh, S., 2012. Neutrophil-to-lymphocyte ratio as a predictor of worsening renal function in diabetic patients (3-year follow-up study). Ren Fail. 34, 571-576.

Bhutta, H., Agha, R., Wong, J., Tang, T.Y., Wilson, Y.G., Walsh, S.R., 2011. Neutrophil-lymphocyte ratio predicts medium-term survival following elective major vascular surgery: A cross-sectional study. Vasc. Endovascular. Surg. 45, 227-231.

Cheung, A.K., Sarnak, M.J., Yan, G., Dwyer, J.T., Heyka, R.J., Rocco, M.V., Teehan, B.P., Levey, A.S., 2000. Atherosclerotic cardiovascular disease risks in chronic hemodialysis patients. Kidney. Int. 58, 353-362.

Daugirdas, J.T., 1993. Second generation logarithmic estimates of single pool variable volume Kt/V: An analysis of error. J. Am. Soc. Nephrol. 4, 1205-1213.

Foley, R.N., Parfrey, P.S., Sarnak, M.J., 1998. Clinical epidemiology of cardiovascular disease in chronic renal disease. Am. J. Kidney. Dis. 32, 112-119.

Honda, H., Ueda, M., Kojima, S., Mashiba, S., Suzuki, H., Hosaka, N., Hirai, Y., Nakamura, M., Nagai, H., Kato, N., Mukai, M., Watanabe, M., Takahashi, K., Shishido, K., Akizawa, T., 2012. Oxidized high-density lipoprotein as a risk factor for cardiovascular events in prevalent hemodialysis patients. Atherosclerosis. 220, 493-501.

Johnson, D.W., Wiggins, K.J., Armstrong, K.A., Campbell, S.B., Isbel, N.M., Hawley, C.M., 2005. Elevated white cell count at commencement of peritoneal dialysis predicts overall and cardiac mortality. Kidney Int. 67, 738-743

Jung, M.R., Park, Y.K., Jeong, O., Seon, J.W., Ryu, S.Y., Kim, D.Y., Kim, Y.J., 2011. Elevated preoperative neutrophil to lymphocyte ratio predicts poor survival following resection in late stage gastric cancer. J. Surg. Oncol. 104, 504-510.

Kalantar-Zadeh, K., Brennan, M.L., Hazen, S.L., 2006. Serum myeloperoxidase and mortality in maintenance hemodialysis patients. Am. J. Kidney. Dis. 48, 59-68.

Kamisli, S., Kamisli,O., Gonullu, S., Kaplan, Y., Ozcan, C., 2012. The prognostic value of increased leukocyte and neutrophil counts in the early phase of cerebral venous sinus thrombosis. Türk. Beyin. Damar. Hast. Derg. 18, 39-42.

Kocyigit, I., Eroglu, E., Unal, A., Sipahioglu, M.H., Tokgoz, B., Oymak, O., Utas, C., 2012. Role of neutrophil/lymphocyte ratio in prediction of disease progression in patients with stage-4 chronic kidney disease. J. Nephrol. 2, 358-65.

Muhmmed Suliman, M.A., Bahnacy Juma, A.A., Ali Almadhani, A.A., Pathare, A.V., Alkindi, S.S., Uwe Werner, F., 2010. Predictiv value of neutrophil to lymphocyte ratio in outcomes of patients with acute coronary syndrome. Arch. Med. Res. 41, 618-622.

National Kidney Foundation., 2003. K/DOQI clinical practice guidelines for bone metabolism and disease in chronic kidney disease. Am. J. Kidney. Dis. 42, 1-201.

Noh, H., Lee, S.W., Kang, S.W., Shin, S.K., Choi, K.H., Lee, H.Y., Han, D.S., 1998. Serum C-reactive protein: A predictor of mortality in continuous ambulatory peritoneal dialysis patients. Perit. Dial. Int. 18, 387-394.

Núñez, J., Núñez, E., Bodí, V., Sanchis, J., Miñana, G., Mainar, L., Santas, E., Merlos, P., Rumiz, E., Darmofal, H., Heatta, A.M., Llàcer, A.. 2008. Usefulness of the neutrophil to lymphocyte ratio in predicting long-term mortality in ST segment elevation myocardial infarction. Am. J. Cardiol. 101, 747-752.

Owen, W.F., Lowrie, E.G., 1998. C-reactive protein as an outcome predictor for maintenance hemodialysis patients. Kidney. Int. 54, 627-636.

Pecoits-Filho, R., Lindholm, B., Stenvinkel, P., 2002. The malnutrition, inflammation, and atherosclerosis (MIA) syndrome - the heart of the 
matter. Nephrol. Dial. Transplant. 17, 28-31.

Pifer, T.B., McCullough, K.P., Port, F.K., Goodkin, D.A., Maroni, B.J, Held, P.J., Young, E.W., 2002. Mortality risk in hemodialysis patients and changes in nutritional indicators: DOPPS. Kidney. Int. 62, 2238-2245.

Reddan, D.N., Klassen, P.S., Szczech., L.A., Coladonato, J.A., O’Shea, S., Owen, W.F., Jr., Lowrie, E.G., 2003. White blood cells as a novel mortality predictor in haemodialysis patients. Nephrol. Dial. Transplant. 18, 1167-1173.

Stenvinkel. P., Heimbürger. O., Lindholm, B., Kaysen, G.A., Bergström, J., 2000. Are there two types of malnutrition in chronic renal failure? Evidence for relationships between malnutrition, inflammation and atherosclerosis (MIA syndrome). Nephrol. Dial. Transplant. 15, 953-960.

Uthamalingam, S., Patvardhan, E.A., Subramanian, S., Ahmed. W., Martin, W., Daley, M., Capodilupo, R., 2011. Utility of the neutrophil to lymphocyte ratio in predicting long-term outcomes in acute decompensated heart failure. Am. J. Cardiol. 107, 433-438.

Villar, E., Remontet, L., Labeeuw, M., Ecochard, R., 2007. Effect of age, gender, and diabetes on excess death in end-stage renal failure. J. Am. Soc. Nephrol. 18, 2125-2134.

Zahorec, R., 2001. Ratio of neutrophil to lymphocyte counts-rapid and simple parameter of systemic inflammation and stress in critically ill. Bratisl. Lek. Listy. 102, 5-14.

Zimmermann, J., Herrlinger, S., Pruy, A., Metzger, T., Wanner, C., 1999. Inflammation enhances cardiovascular risk and mortality in hemodialysis patients. Kidney. Int. 55, 648-658. 